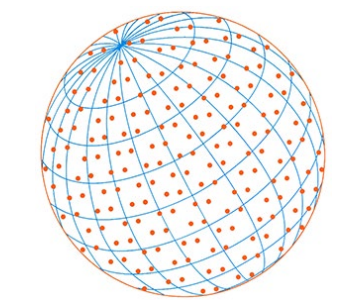

Aerosol and Air Quality Research

\title{
Parallelly Aligned, Activated Carbon Coated Plates Operating as Adsorption Columns for Removing VOCs
}

\author{
Jiyeol Bae ${ }^{1}$, Suho Kim², Soyoung Baek ${ }^{1 *}$ \\ ${ }^{1}$ Department of Land, Water and Environment Research, Korea Institute of Civil Engineering \\ and Building Technology (KICT), Goyang 10223, Korea \\ ${ }^{2}$ Department of Civil \& Environmental Engineering, Yonsei University, Seoul 03722, Korea
}

\begin{abstract}
A semi-pilot-scale adsorption reactor was fabricated to remove a volatile organic compound (VOC) gases mixture (BTEX). Activated carbon (AC) was immobilized by coating it on stainless steel plates using a polyvinyl acetate (PVA) binder, and the open-pore structure was maintained after the coating process. Parallelly aligned plates coated with AC minimized the decrease in pressure by inducing smooth fluid flow and maintained a high removal efficiency even at a high linear velocity. The order of the capacities for adsorption was: xylene $>$ ethyl benzene $>$ toluene $>$ benzene, which was due to their differences in hydrophobicity and molecular weight. The adsorption-desorption process was performed for five successive cycles. The efficiency of removal was evidently the same for all cycles, which makes this reactor a sustainable one.
\end{abstract}

Keywords: Activate carbon coated plate (ACP), Immobilization of powder type adsorbent, BTEX mixed gases adsorption, Adsorption and desorption, van der Waals force

\section{INTRODUCTION}

\section{OPEN ACCESS}

Received: October 1, 2021

Revised: December 3, 2021

Accepted: January 4, 2022

\section{${ }^{*}$ Corresponding Author: \\ soyoung@kict.re.kr}

\section{Publisher:}

Taiwan Association for Aerosol Research

ISSN: $1680-8584$ print

ISSN: 2071-1409 online

Copyright: The Author(s). This is an open access article distributed under the terms of the Creative Commons Attribution License (CC BY 4.0), which permits unrestricted use, distribution, and reproduction in any medium, provided the original author and source are cited.

Expeditious industrialization and urbanization have led to the escalation of volatile organic compounds (VOCs) being emitted into the environment. VOC emissions come from many indoor and outdoor sources, which can be natural as well as anthropogenic (Calton et al., 2010). The indoor sources include printers, heat-exchange systems, household products, office supplies, pressed woods, insulating materials, pipe leakage, and wood stoves. The outdoor sources consist mainly of food processing, paper production, paint drying, petroleum refineries, transportation, chemical industries, textile manufacturing, electronic component manufacturing, cleaning products, metal degreasing, solvents, and automobiles (Drobek et al., 2015; Liotta, 2010; Scire and Liotta, 2012; Ozturk and Yilmaz, 2006). VOCs comprise a range of carbon-based chemicals that evaporate easily at room temperature and are organic compounds having Reid vapor pressures of more than $10.3 \mathrm{~Pa}$ at normal pressure $(101.325 \mathrm{kPa})$ and temperature $(293.15 \mathrm{~K})$ (Olsen and Nielsen, 2001; Li et al., 2009; Ojala et al., 2011). VOCs are considered to be precursors of air pollution and play a crucial, direct role as toxic substances and an indirect role as precursors of smog and ozone (Peng and Wang, 2007; Amann and Lutz, 2000; Rodge, 1990; Lakshmanan et al., 2010; FinlaysonPitts and Pitts, 1997; Molina and Rowland, 1974). Most VOCs are prone to undergo complex photochemical reactions that ultimately produce a variety of toxics and carcinogenic secondary pollutants, including peroxyacyl nitrate (PAN) (Crutzen, 2003) and tropospheric ozone (Aikin et al., 1982), which pose threats to human and plant life (Majumdar et al., 2011). Some VOCs, including formaldehyde, benzene, toluene, ethylbenzene, xylene, and poly-nuclear aromatic hydrocarbons (PAHs) are categorized as potential cancer-causing gases that pose dangers to human life (Hayakawa et al., 2017; Montero-Montoya et al., 2018; McMullin et al., 2018). Aromatic hydrocarbons, which are classed as BTEXs (mixtures of benzene, toluene, and the three xylene isomers) have been the 
focus of attempts to assess the atmospheric pollution in urban areas (Meldrum et al., 2016; Brocco et al., 1997; Coursimault et al., 1995). Even in small concentrations, these compounds are harmful enough to permanently damage the central nervous system. Benzene is recognized as the most toxic gas in the BTEX mixture and is a carcinogen. Hence, ingestion or inhalation of significant quantities of BTEX gases is very dangerous (Moura et al., 2011; Forte et al., 2007).

Many techniques have been developed to mitigate these gases from the atmosphere (Harb et al., 2018; da Costa Filho et al., 2019; Song et al., 2019; Yang et al., 2019). The adsorption technique is one of the most efficient for removing volatile gases from the environment. The application of activated carbon (AC) adsorption systems has been identified as one of the most effective technologies for removing VOCs (Sorial et al., 1994; Yun et al., 1998; Li et al., 2011). At a given mass, AC shows higher surface area and larger pore volume than any other adsorbent (Li et al., 2012; Chiang et al., 2001). However, despite the high potential of powder-type ACs for environmental applications, it also has serious inherent limitations, including that it is difficult to separate and recover from fluids. It also exhibits severe decreases in pressure in fixed-bed column reactors and a retarded mass-transfer rate due to its small particle size (ranging from 1-10 $\mu \mathrm{m}$ ) (El-Safty et al., 2005; Yang et al., 2003; Attard et al., 1997; Nguyen et al., 2000). One possible approach to overcoming the problems of powder-type $A C$ is to immobilize it on a plate. Recently, an approach was proposed that used the immobilizing of a powder adsorbent on an inert support to overcome the large pressure drop when small powder particles are used in an air purification process. Iron based adsorbent coated sand was prepared by the impregnation of sand with a mixed solution of salts, titration of the precipitator, and subsequent drying (Edwards and Benjamin, 1989; Bailey et al., 1992). In addition, studies have attempted to immobilize clay-based adsorbents on a silica plate using an organic binder (Ake et al., 2001, 2003). In the case of AC, in the water-treatment process, the permeability of the membrane was improved by adding a coating of $A C$ to the surface of organic and inorganic membranes using water pressure (Ellerie and Ladner, 2011). These methods were disadvantageous in that the organic binders blocked the pores, reducing the specific surface areas and the pore properties. There was also a problem with the plates detaching from their supports during the purification process. Furthermore, this approach presents other challenges, including the reduction of pore properties during the coating process and complicated synthesis procedures. Therefore, it is necessary to investigate the possibility of enhancing and extending this process by identifying a new approach to preparing plates coated with AC.

In the present study, we attempted to capture BTEX gases in high concentrations using the adsorption technique. Stainless steel plates coated with activated carbon (ACP) behaved as adsorbents to retain the benzene, toluene, ethylbenzene, and xylene in the pores. The VOC mixture was adsorbed when it passed through the surfaces of the ACPs. Then, the ACPs were thermally treated to regenerate the desorption of the mixture of harmful gases. To check the sustainability of the ACPs, the process was repeated several times.

The objectives of this work were to (1) prepare an ACP that would act as adsorbent; (2) observe the physico-chemical properties of that ACP during BTEX adsorption; (3) study the adsorption parameters, including the contact time and the initial concentration of the adsorbate; (4) evaluate the adsorption-equilibrium data obtained in terms of the Freundlich isotherm and the Bohart-Adams model; and (5) test the ACPs at the semi-pilot scale and regenerate them, a cycle that was repeated five times to determine the sustainability of this technology.

\section{METHODS}

\subsection{Preparation of Activated Carbon Coated Plate}

In this study, the binder used to immobilize the powdered $A C$ on the surface of stainless steel plates was polyvinyl acetate (PVA) (HJ-1900, HJ bond; Rep. of Korea). The powdered activated carbon (220 mesh, D. Company; Rep. of Korea) was washed 3 times with boiling water to activate the surface by removing impurities. A viscous slurry was prepared by mixing AC, PVA, and methanol. First, a PVA/methanol solution was prepared by dissolving $100 \mathrm{mg}$ of PVA in $1 \mathrm{~L}$ of methanol. The function of the methanol was to prevent the binder from clogging the pores of the AC. Next, about $250 \mathrm{~g}$ of AC was added to the PVA/methanol solution (PVA: AC = 2:5 wt.\%). To properly coat their surfaces, the stainless steel ACPs were dipped into the slurry mixture for $5 \mathrm{~s}$. 
Then, they were allowed to dry at room temperature for $30 \mathrm{~min}$. Finally, the ACPs were oven dried at $100^{\circ} \mathrm{C}$ for about $3 \mathrm{~h}$ to evaporate the methanol, whose boiling point $=64.7^{\circ} \mathrm{C}$. The size of each ACP specimen was $135 \mathrm{~mm} \times 45 \mathrm{~mm}$. This method was adapted from Kim et al. (2015) with slight modification. This technology has advantages in that the solvent is sufficiently contained in the pores because it uses a relatively low molecular weight ethanol, which later is completely evaporated, enabling the pore characteristics to be maintained during the immobilization process.

\subsection{Characterization}

A portion of the AC on the surface of the steel plate was peeled off and ground up so that its pore properties could be measured. The fine powder of the ACP was characterized as to pore size, total pore volume, and BET surface area and was analyzed. In addition, it was observed under a scanning electron microscope (SEM) to further examine its physical properties.

\subsection{Batch Experiment}

The adsorption capacity of the AC toward a VOC was analyzed with respect to time. $50 \mathrm{ppm}$ of BTEX mixed gases was prepared in each 5-L Tedlar bag, and an ACP piece (weight: $1.2 \mathrm{~g}$ ) was inserted into each one. The Tedlar bags were put into a shaking incubator maintained at room temperature, and the gas samples were collected at $5,10,20,30,60,120,240,300,360$, and $540 \mathrm{~min}$ to monitor the adsorption equilibrium and the changes in concentration.

An adsorption isothermal test was performed as a batch experiment. It was conducted by cutting small $(10 \times 30 \mathrm{~mm})$ pieces of the ACP, with the object of removing the VOC. The BTEX mixture gases, namely benzene, toluene, ethyl benzene, and xylene, were prepared in concentrations of 10 ppm, 20 ppm, 30 ppm, 40 ppm, and 50 ppm The various concentrations of the mixed gases were prepared in 5-L Tedlar bags, and half of each cut piece of ACP (weight $=0.6 \mathrm{~g}$ ) was inserted into a bag. The Tedlar bags were put into a shaking incubator maintained at room temperature, and samples for analysis were taken over $9 \mathrm{~h}$. The concentrations of BTEX gases were analyzed using a GC-MS (Gas chromatograph-mass spectrometry, Thermo Trace GC Ultra, Thermo Scientific). The values obtained for the adsorption equilibrium were tested using Freundlich's isotherm. The Freundlich adsorption model is commonly used to describe non-ideal and reversible adsorption characteristics for a heterogeneous surface. This equation can well explain the multilayer adsorption phenomena and is written as follows Eq. (1).

$\ln Q_{e}=\ln K_{f}+\frac{1}{n} \ln C_{e}$

where $\mathrm{K}_{f}$ and $1 / \mathrm{n}$ are Freundlich constants, related to adsorption capacity and adsorption intensity (heterogeneity factor) respectively. Qe = the rate constant of the BTEX concentration on ACE (adsorbent) $\left(\mathrm{mg} \mathrm{g}^{-1}\right)$, and $\mathrm{Ce}=$ the equilibrium BTEX concentration $\left(\mathrm{mg} \mathrm{L}^{-1}\right)$.

From the value of $1 / n$, we can determine whether the data fits the isotherm model. The slope $(1 / n)$ ranges from $0-1$ and is a measure of the adsorption intensity or heterogeneity of the adsorbent surface, indicating higher heterogeneity as it gets closer to zero. If the value of $1 / n$ is less than 1, it signifies a normal adsorption or that the data fits the Freundlich isotherm adsorption model well. When the value of $1 / \mathrm{n}$ is greater than 1 , it indicates cooperative adsorption, and if the value is greater than 2 , the value is not favorable (Tsai et al., 2003).

\subsection{Semi-Pilot-Scale Experiment}

To evaluate the break-through time and maximum adsorption capacity of the VOC on the ACP, a laboratory-scale continuous reactor was fabricated. The total dimensions of this semi-pilot-scale reactor were $1100 \mathrm{~mm} \times 150 \mathrm{~mm} \times 150 \mathrm{~mm}$, including the gas diffusion zone. The reactor for adsorbing the VOC consisted of eight cells. Each cell was $150 \mathrm{~mm} \times 150 \mathrm{~mm} \times 100 \mathrm{~mm}$, and they were assembled side by side. The dimension of the adsorption field was $800 \mathrm{~mm} \times 150 \mathrm{~mm} \times$ $150 \mathrm{~mm}$. The cross-sectional area of the reactor was $225 \mathrm{~cm}^{2}$. Each cell was equipped with 40 ACPs (each $135 \mathrm{~mm} \times 45 \mathrm{~mm}$ ), and the distance between adjacent ACPs was $1.5 \mathrm{~mm}$, as shown in Fig. 1(A). Each block of 40 upright ACPs was installed at an angle of 65 degrees to its consecutive block of 40 . The arrangement of the ACPs in a single cell led to a laminar flow of the gas in parallel. 


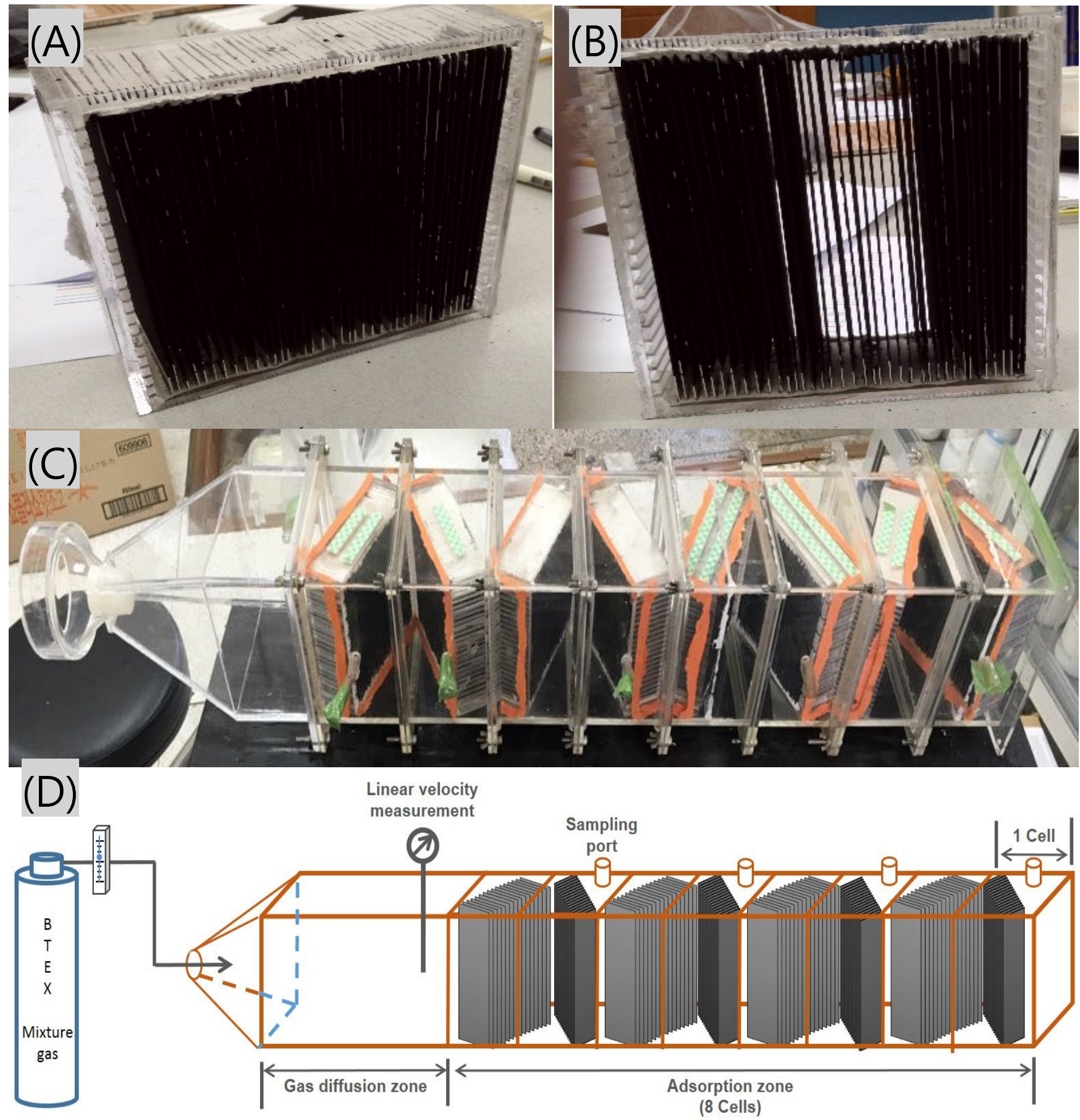

Fig. 1. The above figure gives a detailed information about the ACP reactor for removal of VOCs. (a-b) displays a single cell stacked with 40 activated carbon plates, (c) displays an eight celled semi-pilot scale reactor and (d) diagrammatically represents the experimental set-up of the semi-pilots scale ACP reactor.

To increase the residence time of the gas by providing an angle when the single cells were arranged and to induce turbulence at the rotation point, the gas was temporarily mixed so that it could be introduced at a homogeneous concentration. A BTEX mixture of gases at a concentration of about $50 \mathrm{ppm}$ was introduced into the reactor as an influent gas at a linear velocity of $1 \mathrm{~m} \mathrm{~s}^{-1}$. The test temperature was room temperature $\left(25-27^{\circ} \mathrm{C}\right)$. To confirm the ACP breakthrough on BTEX gas, effluent gas was extracted at different distances. Effluent gases from the second, fourth, sixth, and eighth reactor cells were analyzed, and the cell closest to the influent source was considered a first cell. 
The Bohart-Adams model was implemented to analyze the adsorptive capacity of the semi pilot reactor of adsorption occurring (Song et al., 2015). The Eq. (2) is expressed as

$$
\ln \left(\frac{C_{t}}{C_{0}}\right)=k_{A B} C_{0} t-k_{A B} N_{0}\left(\frac{Z}{U_{0}}\right)
$$

The influent and effluent concentrations $\left(\mathrm{g} \mathrm{m}^{-3}\right)$ are denoted as $C_{0}$ and $C_{t}$, respectively. $K_{A B}$ represents the kinetic constant $\left(\mathrm{m}^{3} \mathrm{~g}^{-1} \mathrm{~min}^{-1}\right), \mathrm{N}_{0}$ is the saturation concentration $\left(\mathrm{g} \mathrm{m}^{-3}\right), t$ is the flow time ( $\mathrm{min}), \mathrm{Z}$ is the bed depth of the fixed-bed column $(\mathrm{m})$, and $\mathrm{U}_{0}$ is the superficial velocity $\left(\mathrm{m} \mathrm{min}{ }^{-1}\right)$. Fig. 1 shows a detailed illustration of the experimental set up.

\subsection{Regeneration of ACP}

After the pores of the AC on the plates were saturated with the VOC mixture, regeneration was needed for further use. Therefore, regeneration of the plates, or desorption of the adsorbed VOC, was performed by heating them at a $100^{\circ} \mathrm{C}$. Generally, desorption is conducted using pressure or heat. In this work, the pieces of ACP, cut to $10 \times 30 \mathrm{~mm}$, were first adsorbed with BTEX gases at a concentration of $10 \mathrm{ppm}$ for $1 \mathrm{~h}$. With the passage of time, about $200 \mu \mathrm{L}$ of gas was withdrawn from the sampling port using a syringe. This was done to track the progression of the surface adsorption phenomenon. After confirming the complete adsorption of the BTEX gases mixture into the pores of the ACP, the vessel was purged of remaining gas with the help of $\mathrm{N}_{2}$ gas for about $30 \mathrm{~min}$. The following method was adapted from Jun et al. (2017). Then, the ACP was regenerated using thermal desorption. Next, the ACP was regenerated at $150^{\circ} \mathrm{C}$. This procedure was repeated five times, the BTEX gases were monitored using GC-MS, and the desorption progress was checked.

\section{RESULTS AND DISCUSSION}

\subsection{Characterization of ACP Plates}

The pores of an activated carbon play a vital role in adsorbing or capturing VOCs and other pollutants. Hence, the pore properties of commercially available powdered AC and ACPs were evaluated using BET and BJH methods. As Table 1 shows, the average pore diameter, BET surface area, and total pore volume of the powdered $A C$ were $2.5 \mathrm{~nm}, 1038.96 \mathrm{~m}^{2} \mathrm{~g}^{-1}$, and $0.5779 \mathrm{~cm}^{3} \mathrm{~g}^{-1}$, respectively, and in the case of the ACPs, these measurements were $2.2 \mathrm{~nm}, 831.00 \mathrm{~m}^{2} \mathrm{~g}^{-1}$, and $0.46 \mathrm{~cm}^{3} \mathrm{~g}^{-1}$, respectively. The values for the BET's surface area and the pore volume of the AC on the ACPs were somewhat smaller than those of the commercial powdered activated carbon.

The decreased values for the ACPs were due to the blockage of a portion of the AC molecules that adhered to the surface of the stainless steel ACPs. When the ACP samples were examined using a SEM, the open pore structure of the AC on the ACPs was clearly identified, even after mixing activated carbon with PVA. Being an organic adhesive, the PVA acted as a cementing material between the stainless steel and the AC, due mainly to the hydrophilic properties exhibited by the mixture of methanol and PVA. This hydrophilic property along with its higher molecular weight $(5,000-40,000)$ kept the mixture from entering into the pores. This was mainly due to the fact that when the ACP was oven dried just after being coated at a temperature higher than the boiling point of methanol, the PVA mixture erupted out of the pores and canopied superficially on the pores. Although the data in Table 1 show a change in the BET surface area and the total pore volume, due mainly to the blocking of a portion of the AC from adhering to the steel ACP, there was a negligible reduction in the value of the average pore diameter, which shows that the ACP's pore size and pore volume were not affected significantly. This shrinking of the BET's

Table 1. Pore properties of commercially available powdered activated carbon and ACP

\begin{tabular}{llll}
\hline & Average pore diameter $(\mathrm{nm})$ & BET surface area $\left(\mathrm{m}^{2} \mathrm{~g}^{-1}\right)$ & Total pore volume $\left(\mathrm{cm}^{3} \mathrm{~g}^{-1}\right)$ \\
\hline Commercial activated carbon & 2.5 & 1038.96 & 0.5779 \\
$\mathrm{ACP}$ & 2.2 & 831.00 & 0.46 \\
\hline
\end{tabular}




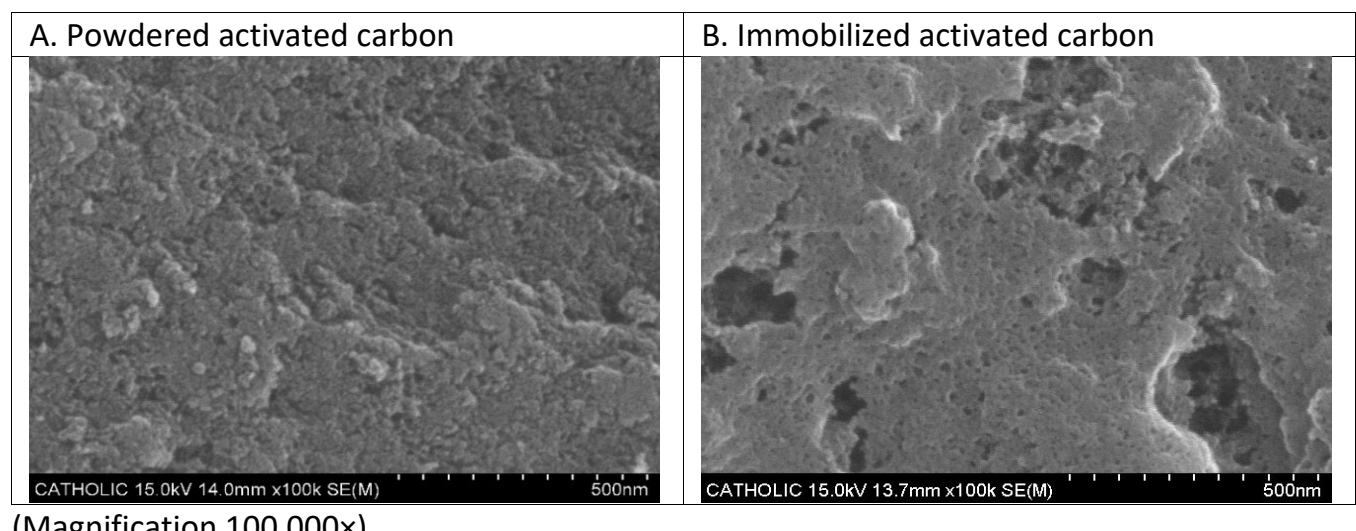

(Magnification 100,000x)

Fig. 2. SEM images of powdered activated carbon and immobilized activated carbon.

surface area could be caused by the inclusion in the calculation of the PVA's mass. These findings ascertain that the ACP's pore structure was undiminished by the coating technique used.

Fig. 2 shows the raw powdered $A C$ and the AC on the ACP surfaces, which were examined using an SEM. The powdered AC was found to have a flat surface and uniform pore distribution. The $A C$ attached to the plate surfaces exhibited irregular pore distribution. Tiny aggregations of AC were observed on the surface of the electrode plate. This was due to the PVA binder, which led to the cohesion of $A C$ particles in the coating mixture.

In the process of immobilizing the AC, only about $20 \%$ of the pores were considered to be blocked, and about $80 \%$ remained unhindered. The recovery of this $80 \%$ in terms of specific surface area was possible because the PVA solution in methanol acted as a hydrophilic agent, whereas $A C$ is hydrophobic in nature. This hydrophobicity and the oven drying of the ACPs at $100^{\circ} \mathrm{C}$ kept the PVA from getting inside the pores of the AC. When the temperature was higher than $64.7^{\circ} \mathrm{C}$ (the boiling point of methanol), the mixture solution of PVA and methanol erupted out of the pores, rejuvenating the concealed cavity of the AC. The heat treatment that evaporated the methanol revived the pores of the AC on the ACPs, even if the ACPs were superficially canopied with PVA. Somehow, this decreased the average pore size. This decreased average pore diameter, BET surface area, and total pore volume of the ACPs all were due to the blockage of a portion of the $A C$ that adhered to the plate surface. The slight reduction in average pore diameter was also partially attributable to the inhibition of the remaining PVA on the surface of the AC. Based on these results, we conclude that the ACP can maintain the adsorption capacity to remove VOC gases.

\subsection{Batch Test}

Fig. 3 shows the removal of the BTEX (a 50-ppm concentration stabilized in $\mathrm{N}_{2}$ ) on the ACPs. The figure shows that benzene exhibited less adsorption than the other three gases in the BTEX mixture. The differences in removal efficiency between benzene and the other gases were not significant until 60 minutes of reaction time. Over the succeeding 60 minutes, the removal efficiency for benzene was about $75 \%$ but more than $83 \%$ for all the other gases. After 240 minutes of reaction time, all the gases attained equilibrium. After this equilibrium, the removal efficiency was $83 \%$ for benzene and more than 95\% for the other gases in the BTEX mixture. The experiment was conducted for a total of 540 minutes, and the removal efficiencies remained apparently congruent for all the gases. In order to confirm the VOCS adsorption efficiency by PVA, a blank sample coated with PVA only on a stainless plate was prepared, and a VOCS adsorption test was performed. As a result, it showed that there was no adsorption effect on VOCS in the plate coated with only PVA Benzene showed the lowest adsorption, followed by toluene, ethylbenzene, and xylene. Because the volatile substances used in this study were mixed gases, they tended to compete with one another in the adsorption reaction. The water-solubility properties of the gases in the mixture, from the greatest to the smallest, were as follows: benzene $>$ xylene $>$ ethylbenzene $>$ toluene. The log Kow values, from the smallest to the greatest, were as follows: benzene $(2.13)<$ toluene (2.69) < xylene (3.13) = ethylbenzene (3.13) (Yang et al., 2011). The relatively high water solubility 


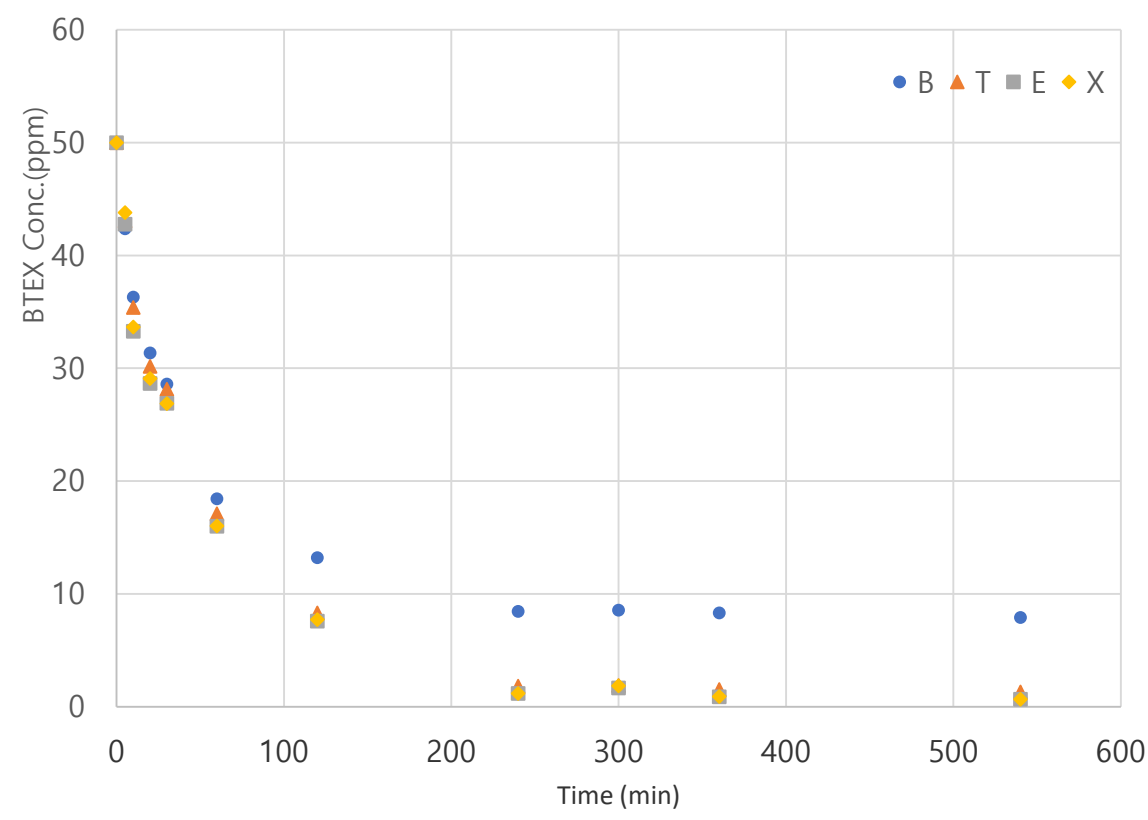

Fig. 3. Effect of time on Benzene, toluene, ethylbenzene and xylene removal.

of benzene and its low Kow value make it more hydrophilic than the other gases in the BTEX mixture. The adsorption capacities of the individual gases in the VOC mixture followed the trend of the Kow value very well. Ethyl benzene and toluene, being the most hydrophobic and the least hydrophilic, respectively, were adsorbed into the ACP pores steadily. Similarly, as described above, the benzene, being less hydrophobic, could not compete with the other gases in the mixture. Another reason for this adsorption trend is contained in the adsorption mechanism itself. The prime mechanism behind the adsorption of a BTEX gas mixture on ACP surfaces is van der Waal's Force of Attraction. The larger the molecule, the higher the contribution of van der Waal's force to the adsorption potential. Ethylbenzene $\left(106.20 \mathrm{~g} \mathrm{~mol}^{-1}\right)$ and xylene $\left(106.20 \mathrm{~g} \mathrm{~mol}^{-1}\right)$, having the largest molecules of the gases in the mixture, exhibited the best adsorption potential. The size of the toluene molecule $\left(92 \mathrm{~g} \mathrm{~mol}^{-1}\right)$ resulted in comparatively lower adsorption potential. Benzene $\left(78.10 \mathrm{~g} \mathrm{~mol}^{-1}\right)$, has the smallest molecule of the gases in the mixture, which clearly explains its lower adsorption capacity regarding the ACP surface (Yang et al., 2011). The non-polar nature of the BTEX mixture gases significantly increased van der Waal's Force of Attraction between the gas molecules and the pores of the AC on the ACPs. The van der Waal's surface areas of the BTEX gases are $110 \AA^{2}, 132 \AA^{2}, 159 \AA^{2}$, and $159 \AA^{2}$, which follow well the adsorption capacity of the ACP. The functional group of $A C$ is an important factor in the adsorption process. In general, AC includes many functional groups, including carboxylic, lactone, phenol, carbonyl, anhydride, ether, and quinone. However, Daifullah and Girgis report that the functional group of AC does not greatly affect non-specific attraction (e.g., van der Waal's force) in micropores (Daifullah and Girgis, 2003). We concluded that the hydrophobicity and molar size of the toluene and the benzene were less than those of the ethylbenzene and the xylene.

Table 2 shows that the slopes $(1 / n)$ of all the BTEX gases were between 0.3245 and 0.8054 , which indicates that the adsorption of all the gases was normal and fitted well with the Freundlich isotherm model. This result indicates that the adsorption of the BTEX into the pores of the AC on the ACP was a multilayer phenomenon, which offers more proof that the main adsorption mechanism behind this process was van der Waal's Forces of Attraction regarding the hydrophobicity and non-polarity of the gases. It also means that the $\mathrm{AC}$ was an efficient adsorbent material, even though attached to the surfaces of thin stainless steel plates. We concluded that this was possible because the major portion of the AC, which comprised the pores, actively participated in the direct adsorption reaction with the BTEX.

As Fig. 4 shows, the $R^{2}$ values for benzene, toluene, ethyl benzene, and xylene were 0.8635 , $0.9083,0.9394$, and 0.9333 , respectively. As Table 2 shows, the value of $Q_{e}$ represents the amounts of the individual gases being adsorbed by the ACPs. The amounts of the gases being 
Table 2. Parameters related to the adsorption of BTEX on Activated carbon coated plates

\begin{tabular}{lllll}
\hline & $Q_{e}$ at $50 \mathrm{ppm}\left(\mathrm{mg} \mathrm{g}^{-1}\right)$ & $1 / \mathrm{n}$ & Log $K$ & $\mathrm{R}^{2}$ (Freundlich) \\
\hline Benzene & 10.41 & 0.3245 & 1.4456 & 0.8635 \\
Toluene & 22.61 & 0.6064 & 2.3087 & 0.9083 \\
Ethylbenzene & 29.06 & 0.6994 & 3.0987 & 0.9394 \\
Xylene & 29.24 & 0.8054 & 3.4791 & 0.9333 \\
\hline
\end{tabular}

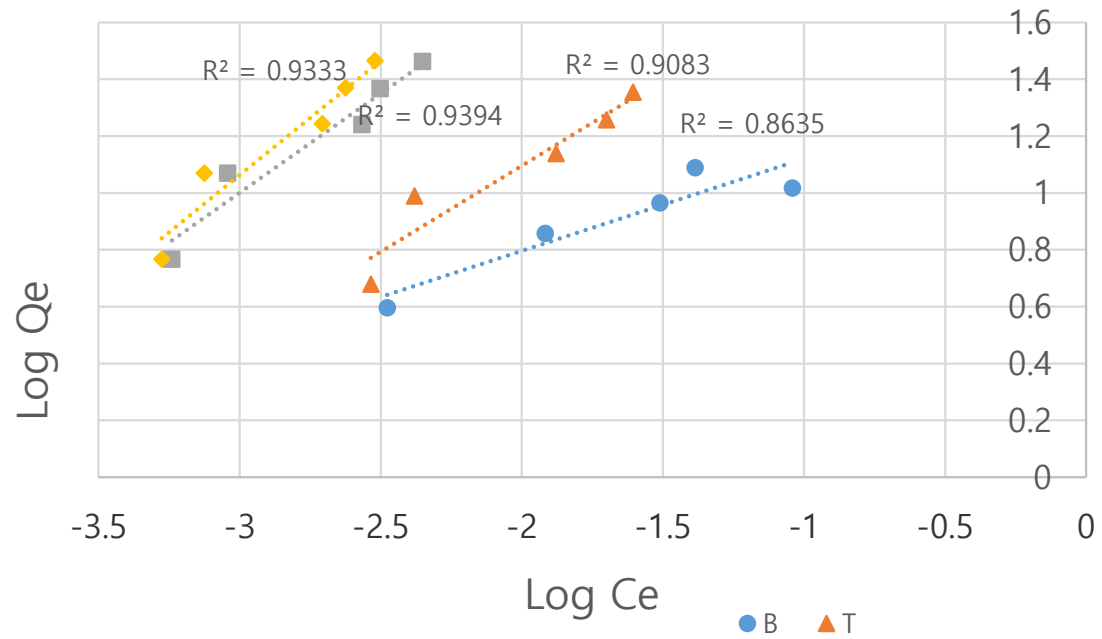

Fig. 4. Freundlich isotherm for Benzene, toluene, ethylbenzene and xylene.

adsorbed on the ACP's surfaces, from the least to the most, were benzene $<$ toluene $<$ ethyl benzene < xylene.

The results of the isothermal adsorption test indicated that the amount of adsorption of each gas showed a high correlation (Fig. 4). Even though the AC immobilized on the thin steel plate was mixed with the point solution, it could be designed by using the usual adsorption type.

\subsection{VOC Removal at Semi-Pilot Scale}

The graphs in Fig. 5 illustrate the break-through curves achieved by the ACPs when a highly concentrated VOC gas mixture was injected into the reactor. The concentration of the BTEX mixture gases injected into the semi-pilot-scale module was about $50 \mathrm{ppm}$. The VOC mixture was introduced into the reactor at a linear velocity of $1 \mathrm{~m} \mathrm{~s}^{-1}$, and the sampling for the adsorption experiment was done at the second, fourth, sixth, and eighth cells of the horizontal reactor. Regardless of the high concentration of the BTEX gases and the high linear velocity, at the second port, about $90 \%$ of the ethylbenzene and $95 \%$ of the xylene were removed within 90 minutes. In the case of toluene, less than $70 \%$ of it was removed at the second port, but by the third port, all was removed. In contrast to these findings, of the four VOC gases in the mixture, benzene showed the least adsorption capability. Two break-through curves were achieved at the second and fourth ports of the reactor. Design parameters were derived based on the results for benzene adsorption. For benzene, the time required to achieve $99 \%$ removal efficiency of the influent gas was less than 25 minutes, based on the effluent gas from the fourth port (eighth cell). The time to achieve $95 \%$ removal efficiency was 9 minutes, based on the effluent gas from the second port (fourth cell), and 62 minutes, based on the effluent gas from the fourth port (eighth cell). The time needed to reach the break-through was measured at about 90 minutes, based on the effluent gas from the second port (fourth cell) and about 170 minutes, based on the effluent gas from the fourth port (eighth cell). Table 3 shows the results of calculating the adsorption amounts per plate area.

Based on the results of the break-through experiments, the amount of benzene adsorbed per plate area of plates coated with AC was calculated using the Bohart-Adams equation, and the factors derived from Table 3 were set, calibrating the Bohart-Adams model so that it can be applied 


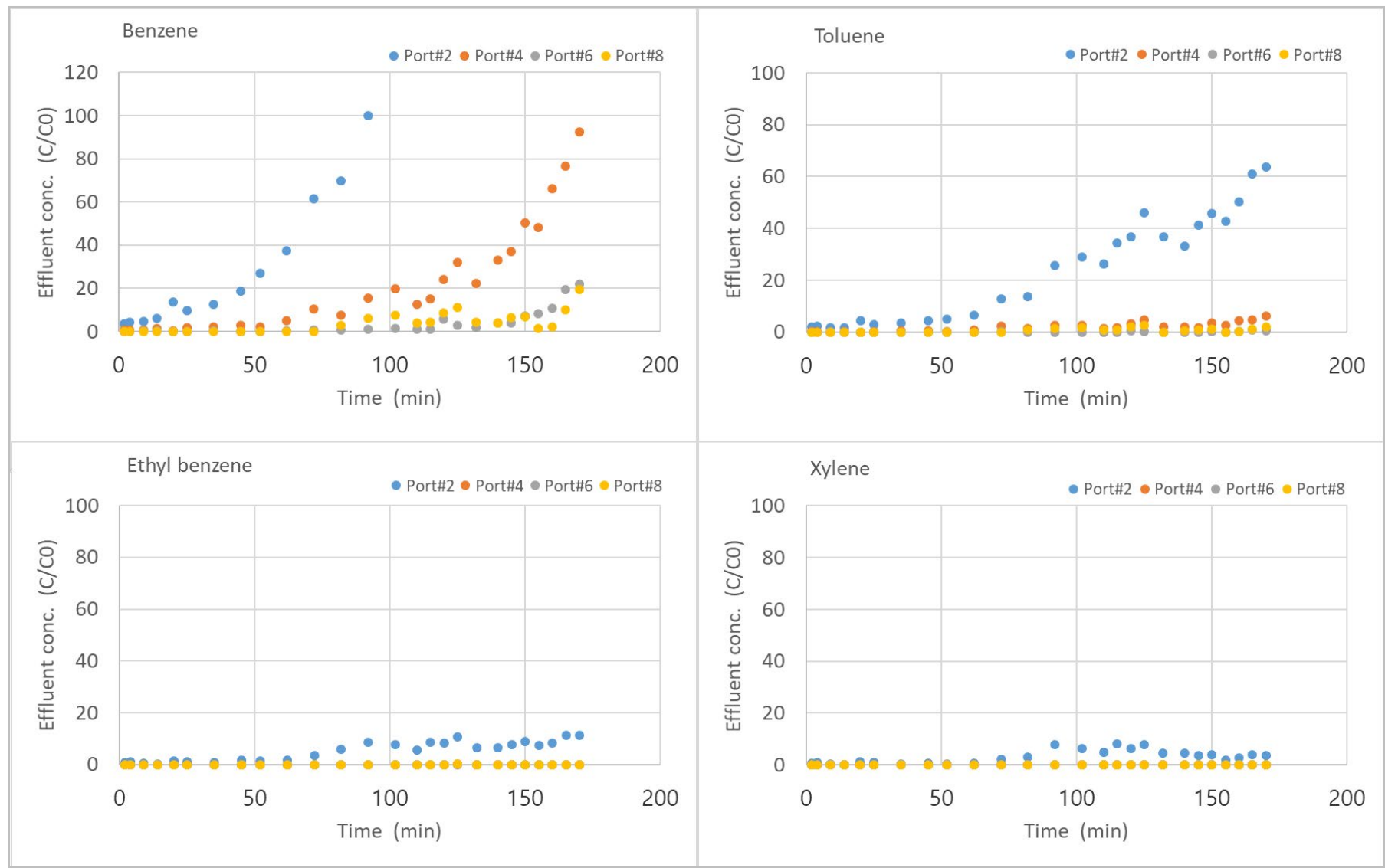

Fig. 5. Breakthrough curves for adsorption of BTEX onto activated carbon coated plates for 50 ppm influent concentration.

Table 3. Bohart-Adam's Equation parameters for adsorption of benzene and toluene on Activated carbon coated plates.

\begin{tabular}{|c|c|c|c|c|c|c|}
\hline & 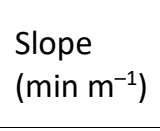 & $\begin{array}{l}\text { Intercept } \\
\text { (min) }\end{array}$ & $\begin{array}{l}\text { Adsorptive capacity } \\
\text { of volume } \\
\left(\mathrm{g} \mathrm{m}^{-3}\right)\end{array}$ & $\begin{array}{l}\text { Bohart-Adams } \\
\text { constants } K \\
\left(\mathrm{~m}^{3} \mathrm{~g}^{-1} \mathrm{~min}^{-1}\right)\end{array}$ & $\begin{array}{l}\text { Minimum } \\
\text { column length } \\
\text { (m) }\end{array}$ & $\begin{array}{l}\text { Adsorptive capacity } \\
\text { of carbon plate } \\
\text { area }\left(\mathrm{g} \mathrm{m}^{-2}\right)\end{array}$ \\
\hline Benzene & 310 & -37 & 3243.375 & 0.4564 & 0.11935 & 8.34 \\
\hline Toluene & 500 & -33 & 5231.25 & 0.5117 & 0.066 & 13.45 \\
\hline
\end{tabular}

with confidence to size the bed. To design the field-scale reactor, the effluent gas standard for the equation was set at $95 \%$ removal efficiency $(2.5 \mathrm{ppm})$. As a result of applying the model, the adsorption amount of the ACP was measured as $8.34 \mathrm{~g} \mathrm{~m}^{-2}$ for benzene and $13.45 \mathrm{~g} \mathrm{~m}^{-2}$ for toluene, and the minimum column lengths necessary to produce a satisfactory effluent concentration were 0.11935 minutes and 0.066 minutes, respectively. This result can be used as an important factor for determining the future filling amount of the plate coated with AC and the service time of the reactor in the real-field scale reactor. The parallelly aligned ACPs minimized the decrease in pressure by inducing smooth fluid flow and maintained a high removal efficiency even at a high linear velocity. This was due to the high adsorption performance of the ACPs. It has been reported that for most VOCs, the amount of adsorption decreases with increasing temperatures in the adsorption reaction because the physical adsorption reaction of the gases is mainly an exothermic reaction and is spontaneous (Giovanny Rincón-Silva et al., 2015). Therefore, we can expect that the removal efficiency of this reactor will increase as the temperature decreases.

Lastly, to check whether the AC was detached from the stainless steel ACP during gas adsorption, fresh air was passed at a high speed, $1 \mathrm{~m} \mathrm{~s}^{-1}$, while detached powder was measured using a dust meter. All dust was measured except for that which leaked. The results of this detachment test showed that the AC was stably attached to the stainless steel plate. 


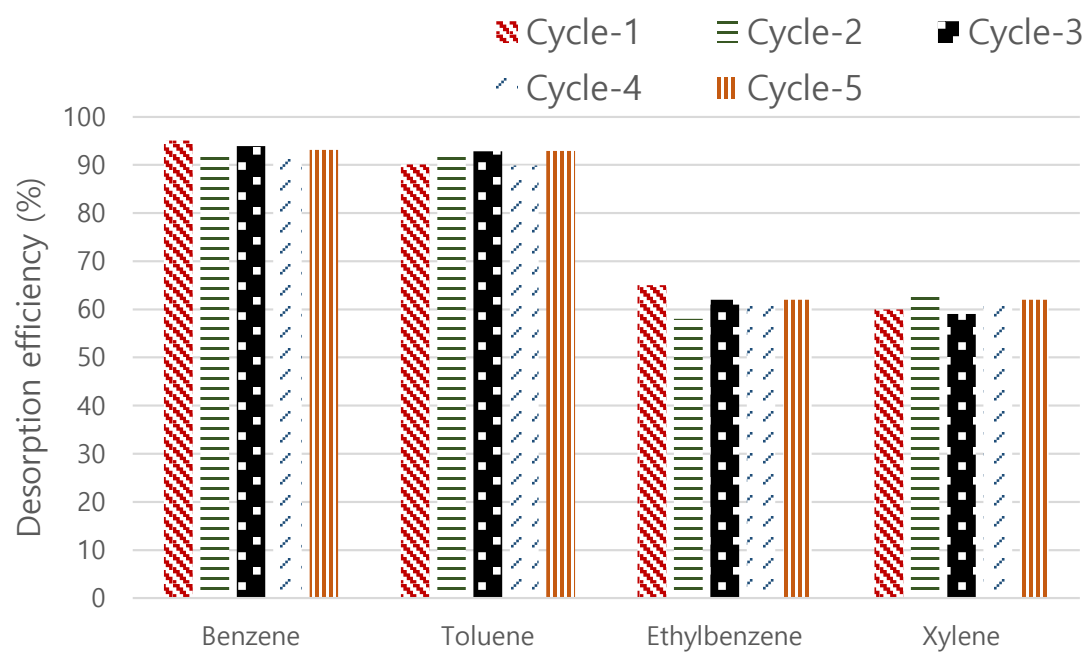

Fig. 6. Desorption results of Benzene, toluene, ethylbenzene and xylene on ACP for regeneration purpose.

\subsection{Regeneration of VOC Adsorbed ACPs}

The ACPs were used repeatedly for up to five consecutive cycles to test the adsorption/desorption/adsorption/desorption of the BTEX gases mixture. This was done to examine the sustainable capability of the fabricated electrode. The bar graph in Fig. 6 shows that the ACPs were able to desorb about $90 \%$ of the benzene and toluene and about $60 \%$ of the ethyl benzene and xylene from the VOC mixture. The desorption efficiency of ethylbenzene and xylene is less than benzene and toluene. As shown in the maximum adsorption results from the pilot test, ethylbenzene and xylene on the ACP have higher adsorption capacity than benzene and toluene, indicating the desorption rate of ethylbenzene and xylene is lower. However, given the excellent adsorption amount for BTEX and the long breakthrough time resulting from the pilot test, the developed system is suitable for field application. The potential to seize the BTEX mixture from the pores of the ACPs remained very much the same in all the cycles, with only negligible discrepancies.

\section{CONCLUSIONS}

In this research, AC was immobilized by coating it on the surface of plates to remove a BTEX gases mixture. This was done in batch mode and continuous mode. The pore properties of the ACPs were reduced by $12 \%$ from those of the raw powdered AC. The methanol in the AC and PVA slurry mixture helped to revive the pores by erupting out the PVA molecules from them when the slurry was heated above its boiling point. For the adsorption isotherm study, the removal of the BTEX from the ACPs was tested with respect to time and then at various initial concentrations of adsorbate. The adsorption isotherm data fitted well with the Freundlich isotherm model. The order of adsorption capacity was xylene $>$ ethyl benzene $>$ toluene $>$ benzene, while the desorption efficiency demonstrated a reverse trend: benzene $>$ toluene $>$ ethylbenzene $>$ xylene. Finally, two break-through curves were achieved in the adsorption of benzene, both of which fitted well with the Bohart-Adams equation. In addition, parallelly aligned AC coated plates minimized the pressure decrease by inducing smooth fluid flow. All the results indicated that this technology is re-generable, which means that it has potential for commercialization as a sustainable environmental field.

\section{ACKNOWLEDGMENTS}

The authors are very grateful for the funds [Project \#20210152-001] provided by the "Korea Institute of Civil Engineering and Building Technology" (KICT), Republic of Korea. 


\section{REFERENCES}

Aikin, A.C., Herman, J.R., Maier, E.J. and McQuillan, C.J. (1982). Atmospheric chemistry of ethane and ethylene. Geophy. Res. 87, 3105-3118. https://doi.org/10.1029/JC087iC04p03105

Ake, C., Mayura, K., Huebner, H., R. Bratton, G., Phillips, T. (2001). Development of porous claybased composites for the sorption of lead from water. J. Toxicol. Environ. Health Part A 63, 459-475. https://doi.org/10.1080/152873901300343489

Ake, C., Wiles, M.C., Huebner, H.J., McDonald, T., Cosgriff, D., Richardson, M.B., Donnelly, K.C., Phillips, T. (2003). Porous organoclay composite for the sorption of polycyclic aromatic hydrocarbons and pentachlorophenol from groundwater. Chemosphere 51, 835-844. https://doi.org/10.1016/S0045-6535(03)00040-7

Amann, M., Lutz, M. (2000). The revision of the air quality legislation in the European Union related to ground.-level ozone. J. Hazard. Mater 78, 41-62. https://doi.org/10.1016/S03043894(00)00216-8

Attard, G.S., Bartlett, P.N., Coleman, N.R.B., Elliott, J.M., Owen, J.R., Wang, J.H. (1997). Mesoporous platinum films from lyotropic liquid crystalline phases. Science $278,838-840$. https://doi.org/10.1126/science.278.5339.838

Bailey, R.P., Bennett, T., Benjamin, M.M. (1992). Sorption onto and recovery of Cr (VI) using ironoxide-coated sand. Water Sci. Technol. 26, 1239-1244. https://doi.org/10.2166/wst.1992.0566

Brocco, D., Fratarcangeli, R., Lepore, L., Petricca, M., Ventrone, I. (1997). Determination of aromatic hydrocarbons in urban air of Rome. Atmos. Environ. 31, 557-566. https://doi.org/10. 1016/S1352-2310(96)00226-9

Carlton, A.G., Pinder, R.W., Bhave, P.V., Pouliot, G.A. (2010). To what extent can biogenic SOA be controlled? Environ. Sci. Technol. 44, 3376-3380. https://doi.org/10.1021/es903506b

Chiang, Y.C., Chiang, P.C., Huang, C.P. (2001). Effects of pore structure and temperature on VOC adsorption on activated carbon. Carbon 39, 523-534. https://doi.org/10.1016/S00086223(00)00161-5

Coursimault, A., Donati, J., Viellard, H. (1995). La pollution automobile due aux hydrocarbures aromatiques monocycliques à Paris. Sci. Total Environ. 169, 17-23. https://doi.org/10.1016/00 48-9697(95)04628-E

Crutzen, P.J. (1979). The role of $\mathrm{NO}$ and $\mathrm{NO}_{2}$ in the chemistry of the troposphere and stratosphere. Annu. Rev. Earth Planet. Sci. 7, 443-472. https://doi.org/10.1146/annurev.ea.07.050179.002303

da Costa Filho, B.M., Silva, G.V., Boaventura, R.A., Dias, M.M., Lopes, J.C., Vilar, V.J. (2019). Ozonation and ozone-enhanced photocatalysis for VOC removal from air streams: Process optimization, synergy and mechanism assessment. Sci. Total Environ. 687, 1357-1368. https://doi.org/10.1016/j.scitotenv.2019.05.365

Daifullah, A.A.M., Girgis, B.S. (2003). Impact of surface characteristics of activated carbon on adsorption of BTEX. Colloids Surf., A 214, 181-193. https://doi.org/10.1016/S0927-7757(02)00 392-8

Drobek, M., Figoli, A., Santoro, S., Navascués, N., Motuzas, J., Simone, S., Algieri, C., Gaeta, N., Querze, L., Trotta, A., Barbieri, G., Mallada, R., Julbe, A., Drioli, E. (2015). PVDF-MFI mixed matrix membranes as VOCs adsorbers. Microporous. Mesoporous. Mater 207, 126-133. https://doi.org/10.1016/j.micromeso.2015.01.005

Edwards, M., Benjamin, M.M. (1989). Adsorptive filtration using coated sand: A new approach for treatment of metal-bearing wastes. J. Water Pollut. Control Fed. 61, 1523-1533. https://www.jstor.org/stable/25043770

El-Safty, S.A., Hanaoka, T., Mizukami, F. (2005). Large-scale design of cubic la3d mesoporous silica monoliths with high order, controlled pores, and hydrothermal stability. Adv. Mater. 17, 4753. https://doi.org/10.1002/adma.200401317

Finlayson-Pitts, B.J., Pitts, J.N. (1997). Tropospheric air pollution: Ozone, airborne toxics, polycyclic aromatic hydrocarbons, and particles. Science 276, 1045-1051. https://doi.org/10.1126/scien ce.276.5315.1045

Harb, P., Locoge, N., Thevenet, E.F. (2018). Emissions and treatment of VOCs emitted from woodbased construction materials: Impact on indoor air quality. Chem. Eng. J. 354, 641-652. https://doi.org/10.1016/j.cej.2018.08.085 
Hayakawa, K., Tang, N., Toriba, A. (2017). Recent analytical methods for atmospheric polycyclic aromatic hydrocarbons and their derivatives. Biomed. Chromatogr. 31, e3862. https://doi.org/ 10.1002/bmc.3862

Jun, T.H., Kim, M.J., Kim, S., Jung, Y.H., Moon, H.R., Kim, K.S. (2017). Evaluation of activated carbon-coated electrode in electrostatic precipitator and its regeneration for volatile organic compounds removal. Water Air Soil Pollut. 228, 110. https://doi.org/10.1007/s11270-0173299-3

Kim, K.S., Kim, S., Jun, T.H. (2015). Activated carbon-coated electrode and insulating partition for improved dust removal performance in electrostatic precipitators. Water Air Soil Pollut. 226, 1-13. https://doi.org/10.1007/s11270-015-2614-0

Lakshmanan, P., Delannoy, L., Richard, V., Méthivier, C., Potvin, C., Louis, C. (2010). Total oxidation of propene over $\mathrm{Au} / \mathrm{xCeO}_{2}-\mathrm{Al}_{2} \mathrm{O}_{3}$ catalysts: Influence of the $\mathrm{CeO}_{2}$ loading and the activation treatment. Appl. Catal., B 96, 117-125. https://doi.org/10.1016/j.apcatb.2010.02.009

Li, L., Liu, S., Liu, J. (2011). Surface modification of coconut shell based activated carbon for the improvement of hydrophobic VOC removal. J. Hazard. Mater. 192, 683-690. https://doi.org/1 0.1016/j.jhazmat.2011.05.069

Li, L., Sun, Z., Li, H., Keener, T.C. (2012). Effects of activated carbon surface properties on the adsorption of volatile organic compounds J. Air Waste Manage. Assoc. 62, 1196-1202. https://doi.org/10.1080/10962247.2012.700633

Li, W.B., Wang, J.X., Gong, H. (2009). Catalytic combustion of VOCs on non-noble metal catalysts. Catal. Today 148, 81-87. https://doi.org/10.1016/j.cattod.2009.03.007

Liotta, L.F. (2010). Catalytic oxidation of volatile organic compounds on supported noble metals. Appl. Catal., B 100, 403-412. https://doi.org/10.1016/j.apcatb.2010.08.023

Majumdar, D., Mukherjeea, A.K., Sen, S. (2011). BTEX in ambient air of a Metropolitan City. J. Environ. Prot. 2, 11. https://doi.org/10.4236/jep.2011.21002

McMullin, T.S., Bamber, A.M., Bon, D., Vigil, D.I., Van Dyke, M. (2018). Exposures and health risks from volatile organic compounds in communities located near oil and gas exploration and production activities in Colorado (USA). Int. J. Environ. Res. Publ. Health 15, 1500. https://doi.org/10.3390/ijerph15071500

Meldrum, K., Gant, T.W., Macchiarulo, S., Leonard, M.O. (2016). Bronchial epithelial innate and adaptive immunity signals are induced by polycyclic aromatic hydrocarbons. Toxicol. Res. 5, 816-827. https://doi.org/10.1039/c5tx00389j

Molina, M.J., Rowland, F.S. (1974). Stratospheric sink for chlorofluoromethanes: Chlorine atomcatalysed destruction of ozone. Nature 249, 810-812. https://doi.org/10.1038/249810a0

Montero-Montoya, R., López-Vargas, R., Arellano-Aguilar, O. (2018). Volatile organic compounds in air: Sources, distribution, exposure and associated illnesses in children. Ann. Globle Health 84, 225. https://doi.org/10.29024/aogh.910

Moura, C.P., Vidal, C.B., Barros, A.L., Costa, L.S., Vasconcellos, L.C., Dias, F.S., Nascimento, R.F. (2011). Adsorption of BTX (benzene, toluene, o-xylene, and $p$-xylene) from aqueous solutions by modified periodic mesoporous organosilica. J. Colloid interface Sci. 363, 626-634. https://doi.org/10.1016/j.jcis.2011.07.054

Nguyen, T.Q., Wu, J., Doan, V., Schwartz, B.J., Tolbert, S.H. (2000). Control of energy transfer in oriented conjugated polymer-mesoporous silica composites. Science 288, 652-656. https://doi.org/10.1126/science.288.5466.652

Ojala, S., Pitkäaho, S., Laitinen, T., Koivikko, N., Brahmi, R., Gaálová, J., Matejova, L., Kucherov, A., Päivärinta, S., Hirschmann, C., Nevanperä, T., Riihimäki, M., Pirilä, M., Keiski, R. (2011). Catalysis in VOC abatement. Top. Catal. 54, 1224-1256. https://doi.org/10.1007/s11244-0119747-1

Olsen, E., Nielsen, F. (2001). Predicting vapour pressures of organic compounds from their chemical structure for classification according to the VOC directive and risk assessment in general. Molecules 6, 370-389. https://doi.org/10.3390/60400370

Ozturk, B., Yilmaz, D. (2006). Absorptive removal of volatile organic compounds from flue gas streams. Process Saf. Environ. Prot. 84, 391-398. https://doi.org/10.1205/psep05003

Peng, J., Wang, S. (2007) Performance and characterization of supported metal catalysts for complete oxidation of formaldehyde at low temperatures. Appl. Catal., B 73, 282-291. https://doi.org/10.1016/j.apcatb.2006.12.012 
Rincón-Silva, N.G., Moreno-Piraján, J.C., Giraldo, L.G. (2015). Thermodynamic study of adsorption of phenol, 4-chlorophenol, and 4-nitrophenol on activated carbon obtained from eucalyptus seed. J. Chem. 2015, 569403. https://doi.org/10.1155/2015/569403

Rodhe, H. (1990). A comparison of the contribution of various gases to the greenhouse effect. Science 248, 1217-1219. https://doi.org/10.1126/science.248.4960.1217

Scirè, S., Liotta, L. (2012). Supported gold catalysts for the total oxidation of volatile organic compounds. Appl. Catal., B 125, 222-246. https://doi.org/10.1016/j.apcatb.2012.05.047

Song, S.K., Shon, Z.H., Kang, Y.H., Kim, K.H., Han, S.B., Kang, M., Bang, J.H., Oh, I. (2019). Source apportionment of VOCs and their impact on air quality and health in the megacity of Seoul, Environ. Pollut. 247, 763-774. https://doi.org/10.1016/j.envpol.2019.01.102

Song, W., Xu, X., Tan, X., Wang, Y., Ling, J., Gao, B., Yue, Q. (2015). Column adsorption of perchlorate by amine-crosslinked biopolymer based resin and its biological, chemical regeneration properties. J. Carbohydr. Chem. 115, 432-438. https://doi.org/10.1016/j.carbpo I.2014.09.010

Sorial, G.A., Papadimas, S.P., Suidan, M.T., Speth, T.F. (1994). Competitive adsorption of VOCs and bom-oxic and anoxic environments. Water Res. 28, 1907-1919. https://doi.org/10.1016/00431354(94)90166-X

Yang, C., Miao, G., Pi, Y., Xia, Q., Wu, J., Li, Z., Xiao, J. (2019). Abatement of various types of VOCs by adsorption/catalytic oxidation: A review. Chem. Eng. J. 370, 1128-1153. https://doi.org/10. 1016/j.cej.2019.03.232

Yang, H., Shi, Q., Liu, X., Xie, S., Jiang, D., Zhang, F., Yu, C., Tu, B., Zhao, D. (2003). Synthesis of ordered mesoporous carbon monoliths with bicontinuous cubic pore structure of la3d symmetry. Chem. Comm. 23, 2842-2843. https://doi.org/10.1039/B209233F

Yang, J.E., Skogley, E.O., Ok, Y.S. (2011). Carbonaceous resin capsule for vapor-phase monitoring of volatile monoaromatic hydrocarbons in soil. Soil Sediment Contam. 20, 205-220. https://doi.org/10.1080/15320383.2011.536596

Yun, J.H., Hwang, K.Y., Choi, D.K. (1998). Adsorption of benzene and toluene vapors on activated carbon fiber at 298, 323, and 348 K. J. Chem. Eng. Data 43, 843-845. https://doi.org/10.1021/ je980069a 